\title{
The effect of silage and hay of regrowth timothy on the cellulolytic bacterial population in the rumen of reindeer
}

\author{
MA Olsen, R Moen, SD Mathiesen \\ Department of Arctic Biology and Institute of Medical Biology, University of Tromso, 9037 Tromso, Norway
}

Semi-domesticated reindeer (Rangifer $t$. tarandus) in northern Norway migrates between summer and winter pastures, and experience large seasonal changes in vegetation types. Reindeer select high quality vascular plants in summer, while lichens constitute a substantial proportion of the winter diet. In winter snow and ice often cover the pasture, exposing the reindeer to periods of acute starvation, and supplementary feeding can prevent losses of animals. Different qualities of timothy silage have been evaluated as food for reindeer, revealing low ability of reindeer to digest rough fibrous timothy (Aagnes et al, 1994, Proc Soc Nutr Physiol, 3, 209). Some individual animals also fail to adapt to high quality timothy silage in winter, resulting in an increased rumen size and a reduced ability of the rumen microbiota to ferment cellulose in vitro. The objective of the present study was to determine if constituents in grass silage could influence the ruminal bacterial populations and their ability to ferment cellulose.

Six reindeer calves were taken directly from a natural winter pasture, three animals were fed silage with $18.8 \%$ dry matter and compared with three animals fed hay of regrowth timothy (Phleum pratense) ad lib for six weeks. The grass were harvested from the same crop.

Rumen solids were obtained by straining the rumen contents through two layers of muslin. The solids were suspended for $30 \mathrm{~min}$ in M8 medium (Olsen et al, 1994, Appl Environ
Microbiol, 60, 4445-4455) containing $0.1 \%$ (w/v) methyl cellulose to detach adherent bacteria from the particles, homogenised and diluted. Colony counts of viable cells were made using a habitat simulating medium (M8V) (Orpin et al, 1985, Appl Environ Microbiol, 50, 144-151). Bacteria were isolated in an acid swollen cellulose medium. Bacterial strains, which were able to hydrolyse carboxymethylcellulose, were incubated in liquid M8 containing Whatman filter paper and $0.01 \%$ $(w / v)$ cellobiose to enumerate the cellulolytic bacterial population. The ability of rumen fluid to ferment cellulose was investigated by incubation of Whatman filter paper with rumen fluid and artificial saliva for $6,24,48$ and 72 hours (Aagnes et al, 1995, Rangifer, 15, 27-35).

The total numbers of viable bacteria (median) were low in all animals fed timothy silage (4.88 $\times 10^{8}$ bacteria/g rumen solids) compared to animals fed hay $\left(72.4 \times 10^{8}\right.$ bacteria/g rumen solids), and we were not able to isolate cellulolytic bacteria from the rumen solids. Cellulolytic bacteria resembling Butyrivibrio fibrisolvens were isolated from all animals fed hay. Reduced ability of the microbiota in the rumen fluid to ferment cellulose in vitro were observed in reindeer fed timothy silage (24\% DMD after $48 \mathrm{~h}$ ) compared to reindeer fed hay ( $36 \%$ DMD after $48 \mathrm{~h}$ ). These findings indicate that timothy silage influence the occurrence of adherent cellulolytic bacteria in the rumen of reindeer. 